\title{
Completion Rates and Clinical Changes of Patients Seeking Non-Invasive Treatment for Low Back Pain in 13 Centres of a Sports Medicine Institute in India
}

\author{
Priyadarshini Rajamani $^{a}$ Hemant Deepak Shewade ${ }^{b, c}$ Debashish Kundu ${ }^{b}$ \\ Kishore Kumar Sekaran ${ }^{a}$ Santhanam Daniel Amalan ${ }^{a}$ Sujatha Pugazhendi ${ }^{a}$ \\ Kannan Pugazhendi ${ }^{a}$

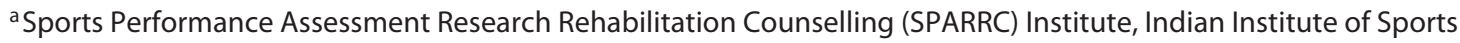 \\ Medicine, Chennai, India; ${ }^{b}$ International Union Against Tuberculosis and Lung Disease (The Union), South East Asia \\ Office, New Delhi, India; ' International Union Against Tuberculosis and Lung Disease (The Union), Paris, France
}

\section{Keywords}

Complementary and alternative medicine $\cdot$ Physical therapy · Manual therapy - Musculoskeletal pain · Rehabilitation

\begin{abstract}
Background/Aim: Low back pain (LBP) is the major cause of disability worldwide. The existing treatments are expensive and associated with complications. The present study aimed to determine the proportion of patients completing therapy and rehabilitation phases and describe the changes in selfreported symptoms and functional disability among LBP patients enrolled in a private sports medicine institute. Methods: This is a cohort study involving review of case records. We studied 2 phases out of 3 of non-invasive treatment of LBP: therapy of around 10 days (myofascial trigger point release therapy, cryotherapy, aqua therapy and acupuncture) and rehabilitation of around 3 weeks (muscle strengthening exercises). Results: A total of 443 patients were enrolled; their mean (SD) age was 46 (15) years, $46 \%$ were male, and 193 (44\%) presented with chronic (>6 months) pain. The numbers of patients who completed the therapy and rehabilitation phases were 327 (74\%) and 115 (26\%), respectively. The median (IQR) visual analogue scale pain scores were 7 (6-9) at entry, 2 (1-3) at completion of therapy and 1 (0-2) at completion of rehabilitation $(p<0.001)$. The median (IQR)
\end{abstract}

functional disability scores were $32(22-53)$ at entry, 15 (626) at completion of therapy and $4(0-14)$ at completion of rehabilitation $(p<0.001)$. Conclusion: Low completion rates were observed. Patients who completed therapy reported reduction in pain and improved functionalities.

(C) 2019 The Author(s)

Published by S. Karger AG, Basel

\section{Abschlussraten und klinische Veränderungen bei nicht-invasiver Behandlung von Schmerzen des unteren Rückens in 13 Zentren eines sportmedizinischen Instituts in Indien}

\section{Schlüsselwörter}

Komplementär- und Alternativmedizin · Physikalische Therapie · Manuelle Therapie · Schmerzen des Muskel- und Skelettsystems · Rehabilitation

\section{Zusammenfassung}

Hintergrund/Zielsetzung: Schmerzen im unteren Rücken ("Kreuzschmerzen") sind weltweit die häufigste Ursache für körperliche Beeinträchtigung. Die verfügbaren Therapieoptionen sind mit hohen Kosten und vielen Komplikationen verbunden. Ziel dieser Studie war es, den Anteil der Kreuzschmerzpatienten zu ermitteln, die an einem
(C) 2019 The Author(s) Published by S. Karger AG, Basel

Karger open access

This article is licensed under the Creative Commons AttributionNonCommercial-NoDerivatives 4.0 International License (CC BYNC-ND) (http//www kargercom/Services/OpenAccessLicense). Usage and distribution for commercial purposes as wess as a tribution of modified material requires written permission.
Dr. Priyadarshini Rajamani, BHMS, MSc

Epidemiology, SPARRC Institute, Indian Institute of Sports Medicine

No. 4, Alwarpet Street

Alwarpet, Chennai 600018 (India)

E-Mail drangelin2003@gmail.com 
privaten sportmedizinischen Institut ihre jeweiligen Therapie- und Rehabilitationsphasen vollständig absolvierten, und die Veränderungen bei Symptomen und funktioneller Beeinträchtigung laut Selbstauskunft der Patienten zu beschreiben. Methoden: Es handelt sich um eine Kohortenstudie mit Sichtung von Patientenakten. Wir untersuchten zwei von drei Phasen nicht-invasiver Kreuzschmerztherapie von etwa 10 Tagen Dauer (Therapie zur Auflösung von myofaszialen Triggerpunkten, Kryotherapie, Wassergymnastik und Akupunktur) bzw. Rehabilitationsmaßnahmen von etwa drei Wochen (Muskelaufbautraining). Ergebnisse: Das mittlere Alter der 443 einbezogenen Patienten betrug (mit Standardabweichung) 46 (15) Jahre; 46\% waren männlich, und 193 (44\%) hatten chronische Schmerzen ( $>6$ Monate). Der Anteil der Patienten, die ihre Therapie- bzw. Rehabilitationsphasen vollständig abschlossen, betrug 327 (74\%) bzw. 115 (26\%). Der Schmerzscore auf der visuellen Analogskala betrug im Median (mit Quartilsabstand) bei Untersuchungsbeginn 7 (6-9), bei Abschluss der Therapie 2 (1-3) und bei Abschluss der Rehabilitation $1(0-2)(p<0,001)$. Der Score für den Grad der Funktionseinschränkung betrug im Median (mit Quartilsabstand) zu Beginn 32 (22-53), bei Abschluss der Therapie 15 (6-26) und bei Abschluss der Rehabilitation $4(0-14)(p<0,001)$. Schlussfolgerung: Die verzeichneten Abschlussraten waren niedrig. Diejenigen Patienten, die ihre Behandlung abschlossen, berichteten von Schmerzreduktion und funktioneller Verbesserung.

(c) 2019 The Author(s)

Published by S. Karger AG, Basel

\section{Introduction}

Among all musculoskeletal (MSK) diseases, low back pain (LBP) and neck pain are considered as the main causes of disability globally. In the Institute of Health Metrics and Evaluation's ranking of the causes of disability-adjusted life years, the ranking of LBP and neck pain increased dramatically between 1990 and 2015. In the ranking of years lived with disability, LBP and neck pain remained in first place over a period of 25 years [1-3].

Common treatment modalities for MSK pain include pharmacological therapies, injection therapies and surgical treatments [4]. Pain management is often expensive in terms of treatment costs and may be temporary and cause complications, including an over-dependence on pharmacological pain relief $[2,3,5]$.

Passive manual therapies, including massage therapy and trigger point release, acupuncture and exercise therapies, such as aqua therapy, yoga, tai chi and aerobics, have been found to reduce pain and functional disabilities in many different settings. It is uncertain whether there is any difference between yoga and other exercises for back- related function or pain, or whether yoga added to exercise is more effective than exercise alone [6]. Complementary health approach (manual therapy, acupuncture, mindfulness, yoga), percutaneous electrical nerve stimulation, education, exercise or pharmacological agents were not effective in producing a clinically significant reduction in pain and disability at the short term and intermediate term compared to sham, usual care or minimal intervention [7]. However, these interventions are noninvasive and have the potential to be a cost-effective alternative to surgery $[5,8-11]$. Trigger point release is proven to be effective in relieving LBP when combined with exercise [12]. Moreover, this pain reduction can be maintained by regular muscle strengthening exercises. The treatment guidelines for non-specific LBP recommend regular physical activity as one of the components of LBP treatment [13]. Another review emphasises the multidisciplinary treatment approach (articular, neural and soft tissue mobilization - SHARANS protocol) in the management of LBP [14].

The completion rates of patients in exercise-based interventions remain a challenge [15]. In India as well as globally, there is limited published information on the completion rates of patients while following complementary and alternative medicine therapy for MSK diseases, including LBP.

The Sports Performance Assessment Research Rehabilitation Counselling (SPARRC) Institute, Indian Institute of Sports Medicine, is a private sports and fitness medicine centre with 13 branches across India focusing on non-invasive treatment protocols. The treatment protocol for LBP involves 3 phases: therapy, rehabilitation and fitness. This study was conducted (1) to determine the proportion of patients completing the therapy and rehabilitation phases and (2) to describe the change in selfreported symptoms and functional disability among those who completed the therapy and rehabilitation phases.

\section{Methods}

Study Design

This was a cohort study involving clinical data from the clinical case records of patients.

\section{Study Setting}

Study Sites

The study was conducted in 13 SPARRC centres across India (Alwarpet, Annanagar, Besant Nagar, Chrompet, Mount Road and Velachery in Chennai; Coimbatore; Tirupur; Indira Nagar and Whitefield in Bengaluru; Hyderabad; Mumbai and Delhi).

Non-Invasive Treatment Protocol

The therapy phase includes a combination of procedures in which the tender muscles and corresponding trigger points that may trigger the pain are identified and treated. Each patient is rec-
Rajamani/Shewade/Kundu/Sekaran/ Amalan/Pugazhendi/Pugazhendi 
ommended to have between 3 and 15 therapy sessions taking place between 3 and 20 days. Each therapy session lasts approximately $60 \mathrm{~min}$. Various therapies used are as follows:

Trigger Point Release Therapy. A manual therapy utilizing "trigger point release pressure," neuromuscular techniques and stretching to relieve the chronically contracted segments of muscles and soft tissue causing painful knots (trigger points), muscle weakness and restricting range of muscle motion. Myofascial trigger point therapy is a unique treatment protocol for the treatment of myofascial pain and dysfunction [16].

Cryotherapy. "Cryotherapy is defined as the therapeutic application of any substance to the body that removes heat from the body, resulting in decreased tissue temperature. It decreases tissue blood flow by causing vasoconstriction, and reduces tissue metabolism, oxygen utilisation, inflammation and muscle spasm" [17]. A common method is icing in which ice packs, ice towels, ice massage, gel packs, refrigerant gases and inflatable splints are used. This method is also used to reduce the recovery time as part of the rehabilitation program after acute and chronic injuries [18].

Acupuncture. Acupuncture is an originally Chinese practice of inserting fine needles through the skin at specific points especially to cure disease or relieve pain (as in surgery). The effect has been explained by Gate Control Theory [19].

Aqua Therapy. A therapy program utilizing the properties of water, designed by a suitably qualified physiotherapist specifically for an individual to improve function, carried out by appropriately trained personnel, ideally in a purpose-built and suitably heated hydrotherapy pool [20].

Pulsating Electromagnetic Field (PEMF). PEMF is a non-invasive, painless treatment for various injuries, bone-related conditions and pains. The treatment works by emitting a pulsating, varying intensity and frequency electromagnetic field, coming from a solenoid placed around the patient [21].

Stretch Release. A rehabilitation technique in which the fingertips are placed over the belly of a large muscle and then spread apart in an effort to stretch the skin and underlying muscle. The stretch is done firmly enough to deform the soft tissue, temporarily stimulating cutaneous and muscle efferents and producing facilitation of the underlying muscle [22].

After $60-80 \%$ pain reduction, patients are moved to the rehabilitation phase where they are provided with specific exercise protocols to regain strength and total functioning of the affected area. Between 10 and 25 sessions over 30-45 days are included in this phase. Once they are considerably relieved from pain and able to do their exercises on their own, patients are provided with a set of exercises to practise at home. Hence, completing the therapy and rehabilitation phase is a proxy for treatment success. Finally, after completing the rehabilitation phase, patients are given fitness exercises to incorporate into their daily lives.

Data for each patient was routinely collected in paper-based case record forms which were maintained at each centre.

\section{Study Population}

Newly enrolled patients with non-specific LBP in 13 centres across India from October 2017 to December 2017 were included. Pregnant women, children under 15 years and patients with known renal disorders were excluded.

\section{Data Variables, Sources of Data and Data Collection}

Data from case record forms of study participants were extracted using a structured data collection instrument. Socio-demographic (age, gender, occupation) and clinical (duration of pain, whether recommended for surgery before self-referral, mechanism of onset of pain, specific related history, weight and height) variables at enrolment were collected. Body mass index was calcu-
Table 1. Demographic and clinical characteristics of patients with low back pain seeking treatment in 13 sports medicine centers in India between October and December $2017(n=443)$

\begin{tabular}{|c|c|c|}
\hline Variables & $n$ & $\%$ \\
\hline Total & 443 & 100 \\
\hline \multicolumn{3}{|l|}{ Age } \\
\hline$<25$ years & 32 & 7.2 \\
\hline $25-34$ years & 74 & 16.7 \\
\hline $35-44$ years & 123 & 27.8 \\
\hline $45-54$ years & 88 & 19.9 \\
\hline $55-64$ years & 71 & 16.0 \\
\hline$\geq 65$ years & 53 & 11.9 \\
\hline Missing & 2 & 0.5 \\
\hline \multicolumn{3}{|l|}{ Gender } \\
\hline Male & 204 & 46.0 \\
\hline Female & 239 & 54.0 \\
\hline \multicolumn{3}{|l|}{ Occupation } \\
\hline Managers and professionals & 100 & 22.6 \\
\hline Homemaker (responsible for family and & & \\
\hline household) ${ }^{\mathrm{a}}$ & 127 & 28.7 \\
\hline Private/self-employed & 54 & 12.3 \\
\hline Retired & 25 & 5.6 \\
\hline Other & 62 & 13.9 \\
\hline Missing & 75 & 16.9 \\
\hline \multicolumn{3}{|l|}{ BMI } \\
\hline Underweight $\left(<18.5 \mathrm{~kg} / \mathrm{m}^{2}\right)$ & 6 & 1.4 \\
\hline Normal $\left(18.5-22.9 \mathrm{~kg} / \mathrm{m}^{2}\right)$ & 66 & 14.9 \\
\hline Overweight $\left(23-27.4 \mathrm{~kg} / \mathrm{m}^{2}\right)$ & 184 & 41.5 \\
\hline Obese $\left(\geq 27.5 \mathrm{~kg} / \mathrm{m}^{2}\right)$ & 158 & 35.7 \\
\hline Missing & 29 & 6.5 \\
\hline \multicolumn{3}{|l|}{ Pain duration } \\
\hline Acute (<180 days) & 230 & 51.9 \\
\hline Chronic (>180 days) & 193 & 43.6 \\
\hline Missing & 20 & 4.5 \\
\hline \multicolumn{3}{|l|}{ Onset of pain } \\
\hline Gradual & 86 & 19.4 \\
\hline Sudden & 357 & 80.6 \\
\hline \multicolumn{3}{|l|}{ Pain attribution } \\
\hline Injury or fall & 17 & 3.8 \\
\hline Medical or surgical condition & 19 & 4.3 \\
\hline Sports injury & 8 & 1.8 \\
\hline Occupation related & 32 & 7.3 \\
\hline Heavy weight lifted & 12 & 2.7 \\
\hline None & 355 & 80.1 \\
\hline \multicolumn{3}{|l|}{ Surgery recommended before self-referral } \\
\hline Yes & 45 & 10.2 \\
\hline No & 398 & 89.8 \\
\hline
\end{tabular}

BMI, body mass index. ${ }^{a}$ A person who is responsible for domestic chores, including childcare, as their primary occupation. In this context, this refers to females taking care of their own family.

lated and classified according to the Asian classification [23]. Data on completion of the therapy and rehabilitation phases (yes/no), the date of completing each phase and the types of sessions in the therapy phase were collected. We measured the following at enrolment (entry), completion of therapy and completion of rehabilitation: self-reported pain score using a visual analogue scale (VAS) 


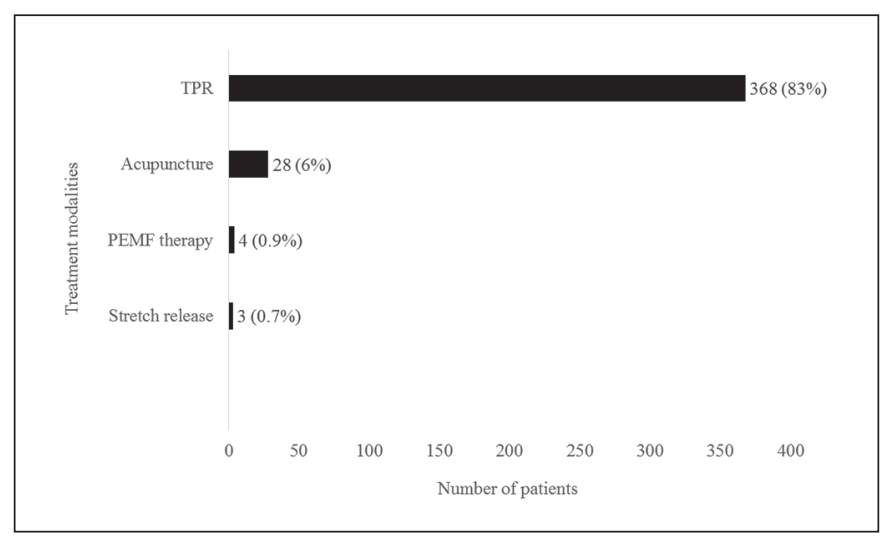

Fig. 1. Treatment modalities for low back pain patients from 13 sports medicine centres in India between October and December 2017 ( $n=443)$. Since combinations of therapies were given, frequencies of therapies were calculated using multiple set analysis; thus, the total may not add up to 443 . TPR, trigger point release; PEMF, pulsed electromagnetic field therapy.

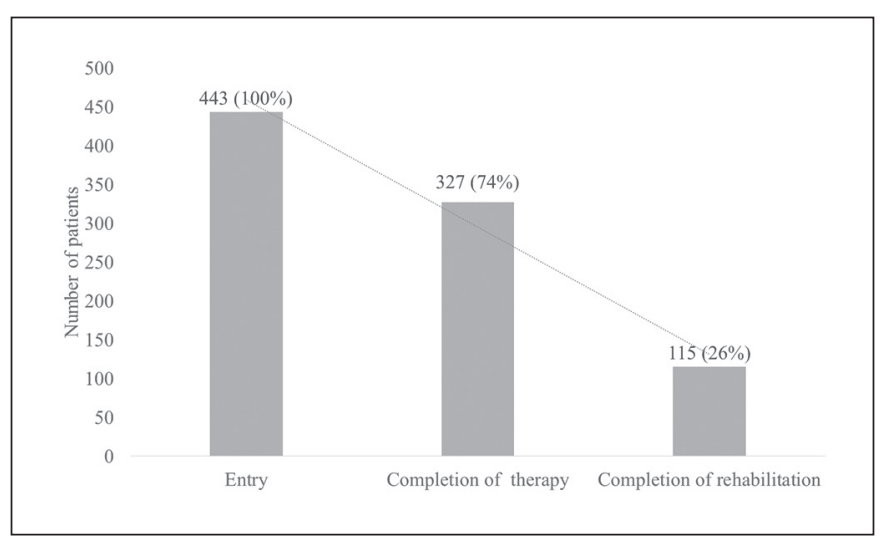

Fig. 2. Number of low back pain patients at entry, completion of therapy and completion of rehabilitation phases from 13 sports medicine centres in India, between October and December 2017 $(n=443)$.

(VAS score: 0 for no pain and 10 for highest severity of pain) and functional disability scale using Oswestry Disability Index (percentage from 0 to 100) [24]. The questionnaire to assess functional disability was administered to the patient as part of the case record form.

\section{Analysis and Statistics}

Data were double-entered and validated using EpiData entry software (version 3.1, EpiData Association, Odense, Denmark). Data analysis was done using STATA (version 12.1 STATA Corp., College Station, TX, USA).

Socio-demographic and clinical variables were summarised using mean (SD), median (IQR), frequencies and proportions. Each patient was followed up for 3 months from enrolment. Completion of the therapy and rehabilitation phases among those enrolled were summarized using cumulative proportions. Duration in each phase was calculated from the dates of enrolment, completion of therapy and completion of rehabilitation (as applicable).

Factors associated with completion of therapy and rehabilitation phase were summarized and inferred using unadjusted/ad- justed relative risks (using log binomial regression) and 0.95 confidence interval (CI).

Among those who completed the therapy and rehabilitation phases, median change in VAS and functional disability score at entry, completion of therapy and completion of rehabilitation were compared and inferred using Friedman test.

\section{Results}

A total of 443 patients were enrolled, and their sociodemographic and clinical characteristics are given in Table 1 . The mean (SD) age of patients was 46 (15) years, and $46 \%$ were male. The median VAS score at baseline was 7 (IQR: 6-8), and median functional disability score was 29 (IQR: 20-44).

The most commonly provided therapy in the therapy phase was myofascial trigger release with ice pack fomentation $(n=368,83 \%)$. However, combinations of other therapies, including acupuncture $(n=28,6 \%)$, pulsed electromagnetic field therapy $(n=4,0.9 \%)$ and stretch release $(n=3,0.7 \%)$, were also used depending on the severity of the pain (Fig. 1).

Of 443 patients, 327 (74\%) completed the therapy and 115 (26\%) completed the rehabilitation phase (Fig. 2). The median number of days spent in the therapy was 10 (IQR: 6-14) and in the rehabilitation phase it was 24 (IQR: 6-24). The factors associated with completion of the therapy and rehabilitation phases are shown in Table 2. Completion of the rehabilitation phase was below $47 \%$ across all subgroups. Men were less likely to complete than women, and the gender difference was statistically significant (adjusted risk ratio [0.95 CI]: 0.59 [0.39, 0.91]).

Of those who completed the rehabilitation phase $(n=$ 115 ), the VAS score and functional disability score were recorded at all 3 time points (entry, completion of therapy and completion of rehabilitation) for 87 (76\%) and 111 (97\%) patients, respectively. These patients were included for the analysis of change in pain score and functional disability.

The median VAS scores at entry, completion of therapy and completion of rehabilitation were 7 (IQR: 6-8), 2 (IQR: $1-3$ ) and 1 (IQR: 0-2), respectively. The median functional disability scores at entry, completion of therapy and completion of rehabilitation were 32 (IQR: 22-53), 15 (IQR: 6-26) and 4 (IQR: 0-14), respectively. There was a significant reduction of both scores across the phases (Fig. 3).

\section{Discussion}

This study assessed the completion rates and clinical changes among adults with LBP that underwent a noninvasive complementary alternative medicine therapy. The study had 3 key findings. 
Table 2. Factors associated with the completion of the rehabilitation phase in the treatment of low back pain among patients seeking treatment from 13 sports medicine centers in India between October and December 2017 $(n=443)$

\begin{tabular}{|c|c|c|c|c|c|}
\hline \multirow[t]{2}{*}{ Variables } & \multirow[t]{2}{*}{$n$} & \multicolumn{2}{|c|}{$\begin{array}{l}\text { Completion of } \\
\text { rehabilitation phase }\end{array}$} & \multirow[t]{2}{*}{ RR (95\% CI) } & \multirow[t]{2}{*}{$\operatorname{aRR}(95 \% \mathrm{CI})$} \\
\hline & & $n$ & $\%$ & & \\
\hline Total & 443 & 115 & 26 & - & - \\
\hline \multicolumn{6}{|l|}{ Age } \\
\hline$<25$ years & 32 & 9 & 28.1 & $1.0(0.6,2.0)$ & $1.8(0.6,2.3)$ \\
\hline 25-34 years & 74 & 20 & 27.0 & $1.0(0.6,1.7)$ & $1.1(0.7,1.9)$ \\
\hline $35-44$ years & 123 & 32 & 26.0 & Ref & Ref \\
\hline 45-54 years & 88 & 24 & 27.2 & $1.0(0.7,1.6)$ & $0.9(0.6,1.4)$ \\
\hline $55-64$ years & 71 & 14 & 19.7 & $0.7(0.4,1.3)$ & $0.6(0.3,1.1)$ \\
\hline$\geq 65$ years & 53 & 16 & 30.1 & $1.1(0.7,1.9)$ & $0.9(0.5,1.5)$ \\
\hline Missing & 2 & 0 & 0 & - & - \\
\hline \multicolumn{6}{|l|}{ Gender } \\
\hline Female & 239 & 77 & 32.3 & Ref. & Ref. \\
\hline Male & 204 & 38 & 18.6 & $0.6(0.4,0.8)$ & $0.6(0.4,0.9)^{\mathrm{a}}$ \\
\hline \multicolumn{6}{|l|}{ Occupation } \\
\hline Managers and professionals & 100 & 24 & 24.0 & $0.7(0.5,1.1)$ & $1.0(0.6,1.6)$ \\
\hline Homemaker (responsible for & & & & & \\
\hline family and household) ${ }^{\mathrm{b}}$ & 127 & 41 & 32.2 & Ref. & Ref. \\
\hline Private/self-employed & 54 & 9 & 16.7 & $0.5(0.3,1.0)$ & $0.8(0.4,1.7)$ \\
\hline Retired & 25 & 6 & 24.0 & $0.7(0.4,1.6)$ & $1.3(0.6,2.9)$ \\
\hline Others & 62 & 14 & 22.6 & $0.7(0.4,1.6)$ & $0.9(0.5,1.7)$ \\
\hline Missing & 75 & 21 & 28.0 & $0.9(0.6,1.4)$ & $1.0(0.7,1.7)$ \\
\hline \multicolumn{6}{|l|}{ BMI } \\
\hline Underweight $\left(<18.5 \mathrm{~kg} / \mathrm{m}^{2}\right)$ & 6 & 2 & 33.3 & $1.2(0.4,4.1)$ & $1.0(0.3,3.5)$ \\
\hline Normal $\left(18.5-22.9 \mathrm{~kg} / \mathrm{m}^{2}\right)$ & 66 & 18 & 27.3 & Ref. & Ref. \\
\hline Overweight (23-27.4 kg/m²) & 184 & 45 & 24.5 & $0.9(0.6,1.4)$ & $0.9(0.6,1.5)$ \\
\hline Obese $\left(\geq 27.5 \mathrm{~kg} / \mathrm{m}^{2}\right)$ & 158 & 38 & 24.1 & $0.9(0.5,1.4)$ & $0.9(0.6,1.5)$ \\
\hline Missing & 29 & 12 & 41.4 & $1.5(0.8,2.7)$ & $1.5(0.8,2.8)$ \\
\hline \multicolumn{6}{|l|}{ Pain duration } \\
\hline Acute $(<180$ days $)$ & 230 & 53 & 23.0 & Ref. & Ref. \\
\hline Chronic (>180 days) & 193 & 55 & 28.5 & $1.2(0.9,1.7)$ & $1.2(0.8,1.6)$ \\
\hline Missing & 20 & 7 & 35.0 & $1.5(0.8,2.9)$ & $1.4(0.8,2.7)$ \\
\hline \multicolumn{6}{|l|}{ Onset of pain } \\
\hline Sudden & 357 & 95 & 26.6 & Ref. & Ref. \\
\hline Gradual & 86 & 20 & 23.3 & $0.9(0.6,1.3)$ & $1.0(0.7,1.6)$ \\
\hline \multicolumn{6}{|l|}{ Pain attribution } \\
\hline Injury or fall & 17 & 8 & 47.1 & $3.0(1.2,7.8)$ & $2.6(1.0,7.1)$ \\
\hline Medical or surgical condition & 19 & 4 & 21.1 & $1.4(0.4,4.4)$ & $1.2(0.4,4.0)$ \\
\hline Sports injury & 8 & 2 & 25.0 & $1.6(0.4,6.8)$ & $0.6(0.4,9.1)$ \\
\hline Occupation related & 32 & 5 & 15.6 & Ref. & Ref. \\
\hline Heavy weight lifted & 12 & 1 & 8.3 & $0.5(0.1,4.1)$ & $2.0(0.4,9.1)$ \\
\hline None & 355 & 95 & 26.8 & $1.7(0.8,3.9)$ & $1.8(0.8,4.2)$ \\
\hline \multicolumn{6}{|c|}{ Surgery recommended before self-referral } \\
\hline No & 398 & 100 & 25.1 & Ref. & Ref. \\
\hline Yes & 45 & 15 & 33.3 & $1.3(0.9,2.1)$ & $1.4(0.9,2.2)$ \\
\hline
\end{tabular}

$\mathrm{RR}$, risk ratio; aRR, adjusted risk ratio; $\mathrm{CI}$, confidence interval; BMI, body mass index; Ref., reference value. ${ }^{\mathrm{a}} p<0.05 .{ }^{\mathrm{b}}$ A person who is responsible for domestic chores, including childcare, as their primary occupation. In this context, this refers to females taking care of their own family.

First, the high pain scores reported at baseline (VAS score) confirm that LBP is a significant problem in this context and remains a major cause of functional disability, as also mentioned in the Institute of Health Metrics and Evaluation's ranking [3]. In addition to high pain scores, almost half of the sample had experienced pain that lasted longer than 6 months, suggesting that many of the patients were experiencing chronic pain that could impact on the quality of their daily life. 


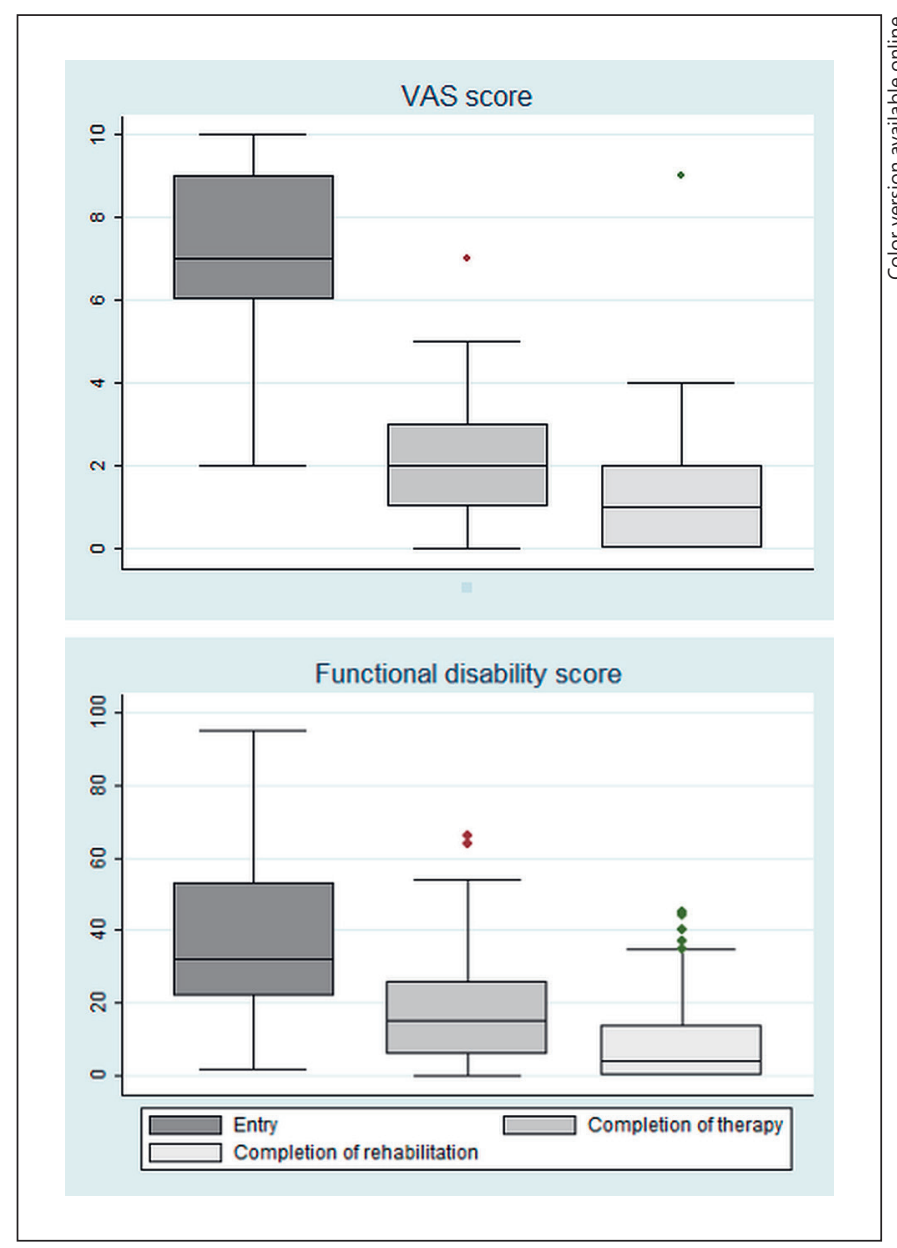

Fig. 3. Box and whisker plots to depict the distribution of VAS and Oswestry Disability Index score at entry, completion of therapy and completion of rehabilitation among patients with low back pain registered and retained in care from 13 sports medicine centres in India between October and December $2017(n=115)$. For the VAS score, the minimum is 0 and the maximum 10; the higher the score, the higher the perceived pain. The functional disability score is expressed as a percentage (minimum 0 and maximum 100; the higher the score, the higher the functional disability). Of those who completed the rehabilitation phase $(n=115)$, the VAS scores and functional disability scores were recorded at all 3 time points (entry, completion of therapy and completion of rehabilitation) among $87(76 \%)$ and 111 (97\%) patients, respectively. These patients were included for the analysis of change in pain score and functional disability. Within-group comparisons were performed with Friedman test. The change was considered statistically significant when $p<0.001$. VAS, visual analogue scale.

Second, low completion rates at the end of rehabilitation were observed, which showed that many patients did not follow the full treatment protocol developed for them [5]. The low completion rates were consistent with findings globally [15]. Possible reasons for discontinuation could be cost, investment of time required, distance from centre and having other commitments, such as work, which meant they did not have the time to continue their treatment protocol [15].
Another possible explanation for the low completion rates was that during the therapy phase, therapists were providing treatment in which the patient remained passive, whereas during rehabilitation, patients were required to conduct strengthening exercises themselves whilst monitored by the instructors. This was supported by the fact that more patients experienced attrition during rehabilitation than during therapy. A lack of motivation to continue the exercises on their own as well as the longer duration of this phase of treatment could also be reasons for the low completion. In addition, patients who were able to carry out strengthening exercises at home on their own may not have wished to spend money continuing treatment at the private centres.

We must also note that patients only continue to the rehabilitation phase if they report a $60-80 \%$ reduction in pain and continue to the fitness phase if they are almost pain-free. This was reflected in the significant reduction in pain and disability scores as patients moved from one phase to the other. Keeping this in mind, the reduction in patient numbers between the therapy and rehabilitation phases may be because they reported an improvement and did not see the need to continue. The other possibility is that patients did not show an improvement and thus either discontinued due to dissatisfaction or were not eligible to move to the rehabilitation phase. However, the reasons for the low completion rate need to be explored with further studies.

Third, males were less likely to complete the treatment than females. A possible reason might be a lack of time due to other commitments, such as work [25].

This study has some key implications. Considering the importance of treating LBP [26], any non-completion should be taken seriously, and changes should be made for the sake of the patient's health. In order to improve completion rates, we would consider adapting the model to ensure that patients understand the importance of the rehabilitation phase through the provision of increased education and information [5]. Health-care providers or therapists need to fully educate the patients about the importance of completing all the phases of treatment and to promote the habitual practice of doing regular exercise for sustaining a reduction in pain and to prevent recurrence of pain.

The patients' VAS scores and functional disability scores were routinely recorded at entry and at the end of each phase to assist with making decisions about the patients' further course of management. In addition to this, it is also recommended to record baseline, end of therapy and end of rehabilitation scores retrospectively at the end of rehabilitation. Quite often, patients' own understanding of the dimension being measured changes after the intervention, and participants may re-adjust their criteria of self-reporting (a phenomenon known as response shift) [27]. 
One of the main limitations of this study is that the low completion rates (115 of 443 participants at entry) limit the validity of the clinical outcomes measures (VAS pain and Oswestry Disability Index). The reason for this is that the outcomes were measured only among those who completed various phases, and we do not know the outcomes of those who did not complete the therapy and/or rehabilitation phases. In addition, reasons for non-completion were not routinely recorded. We were also unable to contact the patients who did not complete therapy and rehabilitation.

\section{Conclusion}

We documented low completion rates among patients with LBP who underwent non-invasive complementary and alternate medicine treatment at 13 centres of a private sports and fitness medicine institute in India. Future assessments should include a qualitative exploration of the reasons for non-completion from the perspective of providers and patients, as this could assist in ensuring higher completion rates in future. However, among patients who completed, the reductions in pain and functional disabilities are notable.

\section{Acknowledgements}

This research was conducted through the Structured Operational Research and Training Initiative (SORT IT), a global partnership led by the Special Programme for Research and Training in Tropical Diseases at the World Health Organization (WHO/ TDR). The model is based on a course developed jointly by the International Union Against Tuberculosis and Lung Disease (The Union) and Médecins sans Frontières (MSF/Doctors Without Borders). The specific SORT IT programme which resulted in this publication was jointly developed and implemented by: The Union South-East Asia Office, New Delhi, India; the Centre for Operational Research, The Union, Paris, France; the Operational Research Unit (LuxOR), MSF Brussels Operational Center, Luxembourg; Department of Preventive and Social Medicine, Jawaharlal Institute of Postgraduate Medical Education and Research, Puducherry, India; Department of Community Medicine, GMERS Medical College, Vadodara, India; Department of Community Medicine, ESIC Medical College and PGIMSR, Bengaluru, India; Department of Community Medicine, Sri Manakula Vinayagar Medical College and Hospital, Puducherry, India; Department of Community Medicine, Velammal Medical College Hospital and Research Institute, Madurai, Tamil Nadu; and National Institute for Research in Tuberculosis, Chennai, India.

We are expressing our special gratitude to Dr Emilie Venables, Luxembourg Operational Research Unit, Médecins Sans Frontières, Luxembourg City, Luxembourg, Division of Social and Behavioral Sciences, School of Public Health and Family Medicine, University of Cape Town, Cape Town, South Africa, for her contribution to the conception/design of the protocol, data analysis/ interpretation and critically reviewing the paper.

\section{Statement of Ethics}

Ethics approval was obtained from the Universal Ethics Committee, Aurous Health Care Research and Development India Private Limited, Chennai, India, and the Ethics Advisory Group of the International Union Against Tuberculosis and Lung Disease (The Union), Paris, France. The SPARRC institute also granted administrative approval before commencing the study. As this was a record review of clinical data, a waiver of written informed consent was sought and approved by the ethics committees.

Permission to publish this article was obtained from the institution before submission. However, the manuscript did not reveal any identifier of the participants in any of the content and thus may not need any formal consent form to be signed by the institution but can be obtained if necessary.

\section{Disclosure Statement}

The authors have no conflicts of interest to declare.

\section{Funding Sources}

The training program, within which this paper was developed, and the open access publication costs were funded by the Department for International Development (DFID), UK, and La Fondation Veuve Emile Metz-Tesch, Luxembourg. The funders had no role in study design, data collection and analysis, decision to publish, or preparation of the manuscript.

\section{Author Contributions}

P.R.: Principal investigator and corresponding author, conception/design of the protocol, acquisition of data, data analysis/interpretation, drafting/critically reviewing the paper, giving approval for the final version to be published.

H.D.S. and D.K.: Conception/design of the protocol, data analysis/interpretation, critically reviewing the paper, giving approval for the final version to be published.

K.K.S., S.D.A., S.P.: Conception/design of the protocol, data collection, critically reviewing the paper, giving approval for the final version to be published:

K.P.: Senior author, overall supervisor, conception/design of the protocol, critically reviewing the paper, giving approval for the final version to be published.

\section{References}

1 Woolf AD. Global burden of osteoarthritis and musculoskeletal diseases. BMC Musculoskelet Disord. 2015 Dec;16(Suppl 1):S3.

2 Babatunde OO, Jordan JL, Van der Windt DA, Hill JC, Foster NE, Protheroe J. Effective treatment options for musculoskeletal pain in primary care: A systematic overview of current evidence. PLoS One. 2017 Jun; 12(6): $\mathrm{e} 0178621$.

3 Institute of Health Metrics and Evaluation (IHME). Rethinking Development and Health - Findings from the Global Burden of Disease Study [Internet]. Seattle, Washington; 2016 [cited 2017 Sep 8]. Available from: http:// www.healthdata.org/sites/default/files/files/images/news_release/2016/IHME_GBD2015.pdf 
4 Chou R, Deyo R, Friedly J, Skelly A, Hashimoto R, Weimer M, et al. Noninvasive Treatments for Low Back Pain [Internet]. Rockville (MD): Agency for Healthcare Research and Quality (US); 2016 [cited 2018 Jun 15]. Available from: http://www.ncbi.nlm.nih.gov/ pubmed/26985522

5 Foster NE, Anema JR, Cherkin D, Chou R, Cohen SP, Gross DP, et al.; Lancet Low Back Pain Series Working Group. Prevention and treatment of low back pain: evidence, challenges, and promising directions. Lancet. 2018 Jun;391(10137):2368-83.

6 Wieland LS, Skoetz N, Pilkington K, Vempati R, D'Adamo CR, Berman BM. Yoga treatment for chronic non-specific low back pain. Cochrane Database Syst Rev. 2017 Jan; 1:CD010671.

7 Nascimento PR, Costa LO, Araujo AC, Poitras S, Bilodeau M. Effectiveness of interventions for non-specific low back pain in older adults. A systematic review and meta-analysis. Physiotherapy. 2019 Jun;105(2):147-162.

8 Iversen MD. Managing Hip and Knee Osteoarthritis with Exercise: What is the Best Prescription?. Ther Adv Musculoskelet Dis. 2010 Oct;2(5):279-90.

9 Tsertsvadze A, Clar C, Court R, Clarke A, Mistry H, Sutcliffe P. Cost-effectiveness of manual therapy for the management of musculoskeletal conditions: a systematic review and narrative synthesis of evidence from randomized controlled trials. J Manipulative Physiol Ther. 2014 Jul-Aug;37(6):343-62.

10 Chang DG, Holt JA, Sklar M, Groessl EJ. Yoga as a treatment for chronic low back pain: A systematic review of the literature. J Orthop Rheumatol. 2016 Jan;3(1):1-8.

11 Yan JH, Gu WJ, Sun J, Zhang WX, Li BW, Pan L. Efficacy of Tai Chi on pain, stiffness and function in patients with osteoarthritis: a meta-analysis. PLoS One. 2013 Apr;8(4):e61672.

12 Ajimsha MS, Daniel B, Chithra S. Effectiveness of myofascial release in the management of chronic low back pain in nursing professionals. J Bodyw Mov Ther. 2014 Apr;18(2): 273-81.

13 Royal College of General Practitioners (UK). Low Back Pain: Early Management of Persistent Non-specific Low Back Pain [Internet]. London: Royal College of General Practitioners (UK); 2009 [cited 2018 Jun 11]. Available from: http://www.ncbi.nlm.nih.gov/ pubmed/20704057

14 Sharan D, Rajkumar JS, Mohandoss M, Ranganathan R. Myofascial low back pain treatment. Curr Pain Headache Rep. 2014 Sep; 18(9):449.

15 Forkan R, Pumper B, Smyth N, Wirkkala H, Ciol MA, Shumway-Cook A. Exercise adherence following physical therapy intervention in older adults with impaired balance. Phys Ther. 2006 Mar;86(3):401-10.

16 Janssens LA. Trigger point therapy [Internet]. Probl Vet Med. 1992 Mar;4(1):117-24. [cited 2018 Dec 4]. Available from: https://physioworks.com.au/massage-1/trigger-point-therapy

17 Nadler SF, Weingand K, Kruse RJ. The physiologic basis and clinical applications of cryotherapy and thermotherapy for the pain practitioner [Internet]. Pain Physician. 2004 Jul; 7(3):395-9. [cited 2019 Apr 24]. Available from: https://www.painphysicianjournal. com/current/pdf?article=MTU3\&journal=20

18 Swenson C, Swärd L, Karlsson J. Cryotherapy in sports medicine. Scand J Med Sci Sports. 1996 Aug;6(4):193-200.

19 Acupuncture/Definition of Acupuncture by Merriam-Webster [Internet]. [cited 2019
May 1]. Available from: https://www.merriam-webster.com/dictionary/acupuncture

20 ATACP. About the Aquatic Therapy Association of Chartered Physiotherapists (ATACP) [Internet]. 2014 [cited 2018 Dec 4]. Available from: https://atacp.csp.org.uk/content/aboutatacp

21 Steenblock D. Pulsed Electromagnetic Field Therapy (PEMF) [Internet]. 2014 [cited 2019 May 1]. Available from: https://innovativemedicine.com/solutions/pulsed-electromagnetic-field-therapy/

22 Stretch release | Definition of stretch release by Medical Dictionary [Internet]. [cited 2018 Dec 6]. Available from: https://medical-dictionary. thefreedictionary.com/stretch+release

23 Nishida C; WHO Expert Consultation. Appropriate body-mass index for Asian populations and its implications for policy and intervention strategies. Lancet. 2004 Jan; 363(9403):157-63.

24 Oswestry Low Back Pain Disability Questionnaire [Internet]. [cited 2018 Jun 13]. Available from: http://www.rehab.msu.edu/_files/_ docs/oswestry_low_back_disability.pdf

25 Silva MA, Zablocki CJ. Predictors of Retention in Physical Therapy: Client-, Disease-, and Treatment-related Factors [Internet]. [cited 2018 Jun 13]. Available from: https:// pdfs.semanticscholar.org/ba $1 \mathrm{e} / \mathrm{e} 4 \mathrm{a}-$ 08be0fdfb45c6836f13ff3abd876ef2ea.pdf

26 Buchbinder R, van Tulder M, Öberg B, Costa LM, Woolf A, Schoene M, et al.; Lancet Low Back Pain Series Working Group. Low back pain: a call for action. Lancet. 2018 Jun; 391(10137):2384-8.

27 Levinson W, Gordon G, Skeff K. Retrospective Versus Actual Pre-Course Self-Assessments. Eval Health Prof. 1990 Dec;13(4):44552. 